\title{
Exposição de fibroblastos da cápsula de Tenon de pterígios à ciclosporina $0,05 \%$
}

\author{
Exposure of Tenon's capsule fibroblasts of pterygium to cyclosporin $0.05 \%$
}

\author{
Laura Almeida Hercules ${ }^{1}$ \\ Magda Massae Hata Viveiros ${ }^{2}$ \\ Silvana Artioli Schellini ${ }^{3}$ \\ João Candeias ${ }^{4}$ \\ Carlos Roberto Padovani ${ }^{5}$
}

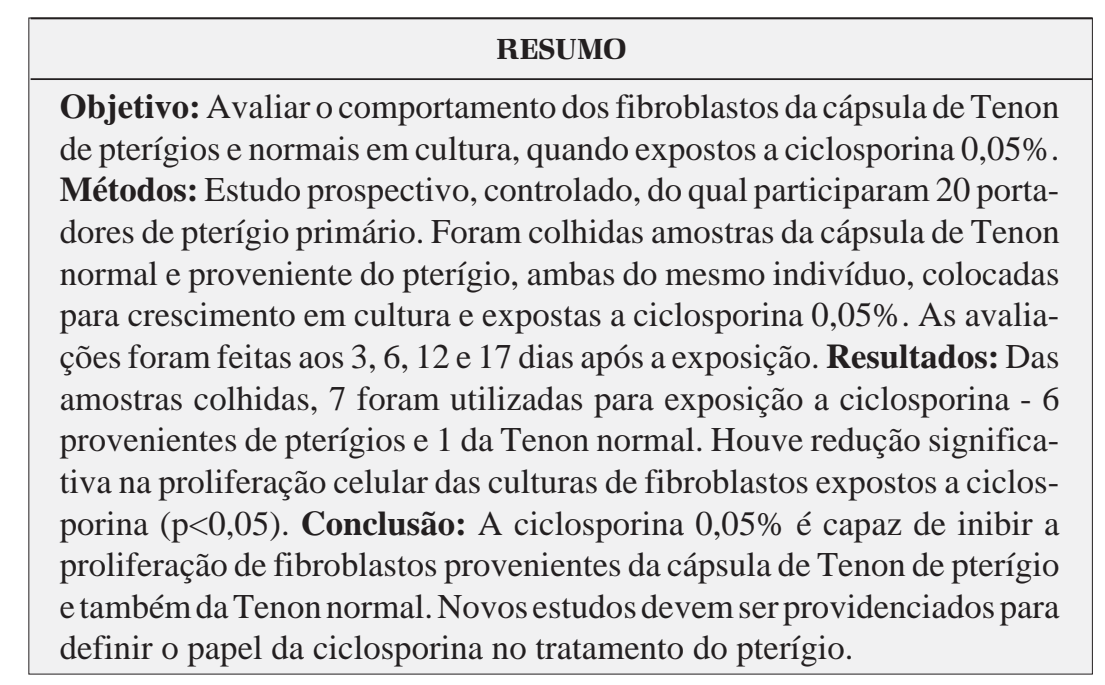

Descritores: Pterígio; Ciclosporinas; Imunossupressores; Técnicas de cultura de células; Fibroblastos

\section{INTRODUÇÃO}

O pterígio ainda tem etiopatogênese incerta, provavelmente multifatorial e seu desenvolvimento relaciona-se com exposição dos pacientes a fatores ambientais, como vento, poeira, radiação ultra-violeta, que alterariam as células germinativas limbares, apesar de não ser conhecida em outros animais e não ter sido possível reproduzir a lesão em modelos experimentais ${ }^{(1-2)}$.

O desconhecimento de todas as variáveis envolvidas na gênese do pterígio impede que uma das vertentes do tratamento, a redução ou ausência do contato com os fatores desencadeantes, seja proposta. Além disso, após a remoção cirúrgica e uso de medicamentos adjuvantes, como os pacientes continuam expostos a inúmeros fatores que podem estar envolvidos na gênese do pterígio, muitos deles ainda desconhecidos, há impossibilidade de avaliação direta da possibilidade de cura frente a determinado procedimento. Por este motivo, estudos in vitro, envolvendo culturas celulares, podem controlar melhor as variáveis que determinam seu desenvolvimento e recidiva, excluindo a influência dos múltiplos fatores externos.

Pesquisando apoptose e a expressão de genes a ela relacionados (p53, bcl-2 e bax), em conjuntiva normal e em pterígios, foi observado que a interrupção no curso normal do processo de apoptose, pode estar envolvida no desenvolvimento do pterígio ${ }^{(3)}$.

A apoptose é ativada pela ciclosporina A, que pode ter sua atividade mediada e potencializada pela ativação do supressor de tumor $\mathrm{p} 53^{(4)}$.

Estudo pregresso, demonstrou que a ciclosporina, quando utilizada por 
via sistêmica, foi capaz de inibir seletivamente os neovasos da córnea de camundongos, induzidos pelo fator de crescimento vascular endotelial $(\mathrm{VEGF})^{(5)}$.

O mecanismo imunológico está envolvido na patogênese do pterígio, havendo hipersensibilidade dos tipos 1 e 3, com aumento da concentração tecidual de imunoglobulinas IgE, IgG, IgA e C3 em portadores de pterígio ${ }^{(6-7)}$.

Aliado à hipótese da inflamação crônica ser o fator que gera o crescimento da conjuntiva sobre a córnea, outra condição que também se supõe estar associada com inflamação mediada por linfócitos T é a síndrome do olho $\operatorname{seco}^{(8)}$.

A ciclosporina A $0,05 \%$ tópica, assim como mesma droga a $2 \%$, são utilizadas para tratamento do olho seco e da ceratoconjuntivite vernal por via tópica ${ }^{(9-11)}$. Culturas de fibroblastos oriundos de indivíduos normais e pacientes com ceratoconjuntivite vernal e penfigóide foram expostas a diferentes concentrações de ciclosporina, observando-se que, em doses maiores que $10 \mu \mathrm{g} / \mathrm{ml}$, houve significativa redução da proliferação e migração celular, com indução de apoptose de maneira dose-dependente, o que comprovou que a exposição a ciclosporina modifica diretamente o comportamento dos fibroblastos, sendo indicado o seu uso em desordens conjuntivais hiperproliferativas ${ }^{(12)}$.

O exato mecanismo de ação da ciclosporina não é totalmente conhecido. Quando administrada sistemicamente, a ciclosporina apresenta atividade imunossupressora. Em pacientes cuja produção de lágrimas é supostamente suprimida devido à inflamação ocular associada à ceratoconjuntivite seca, acredita-se que a ciclosporina emulsão apresenta atividade imuno-moduladora parcial. Em outros indivíduos, nos quais a ceratoconjuntivite seca possui outra gênese, pode levar à diminuição da apoptose de células epiteliais conjuntivais e proteção contra perda de células globosas ${ }^{(13)}$.

Estudo da distribuição da ciclosporina A na córnea, após administração oral ou tópica, demonstrou que a aplicação tópica é capaz de atingir altos níveis no epitélio corneal, maiores que aqueles alcançados pela administração via oral ${ }^{(14)}$.

O objetivo deste trabalho foi estudar o comportamento dos fibroblastos da cápsula de Tenon normal e de pterígios primários em cultura, quando expostos a ciclosporina $0,05 \%$.

\section{MÉTODOS}

Trata-se de estudo prospectivo e controlado, desenvolvido na Faculdade de Medicina de Botucatu - UNESP, São Paulo, no ano de 2005, com a aprovação da Comissão de Ética em Pesquisa em Seres Humanos, desta mesma Instituição (CEP 408/2002).

\section{Pacientes estudados}

Participaram do presente estudo 20 portadores de pterígio, todos localizados no setor nasal.

Todos os indivíduos foram operados por dois dos autores, tendo sido removidos o pterígio e fragmentos da cápsula de
Tenon da região do pterígio e da cápsula de Tenon sadia, localizada no fórnice temporal inferior, do mesmo olho acometido. O primeiro espécime a ser removido foi o tecido são.

Imediatamente após a remoção, os fragmentos de cápsula de Tenon foram acondicionados em tubos Ependorff estéreis e hermeticamente fechados, sendo estocados à temperatura de $5^{\circ} \mathrm{C}$.

\section{Grupos experimentais}

Grupo Pterígio: fizeram parte da amostra de pterígios, lesões de tamanhos variados, todas primárias.

Grupo Tenon normal: obtida do mesmo indivíduo portador de pterígio. Por causa disso, adotou-se, como critério de exclusão, os portadores de pterígio temporal e nasal, no mesmo olho.

Todas as culturas foram acompanhadas e examinadas quanto à proliferação de fibroblastos e, após cultivo, subcultivos e exposição, foram avaliadas em quatro momentos experimentais: 3, 6, 12 e 17 dias após a semeadura, como descrito a seguir.

\section{Metodologia para o processamento das amostras e cultivo celular}

\subsection{Cultivo celular}

As cápsulas de Tenon dos pterígios e os fragmentos de cápsula de Tenon normal foram transportadas em tubos Ependorff até o laboratório de Imunologia do Departamento de Microbiologia e Imunologia do Instituto de Biociências da Universidade Estadual Paulista - UNESP, em período inferior a 3 horas após a exérese, para processamento das amostras.

Sob condições de assepsia e em câmara de fluxo laminar, as amostras foram colocadas em placas de Petri de $35 \mathrm{~mm}$ e lavadas para a remoção de células sanguíneas com meio DMEM/F12 (Gibco - USA, suplementado com $5 \mathrm{ml} / \mathrm{l}$ de vitaminas TC minimal Eagle 100X, 0,01 U/ml de insulina, 1,4 g/l de bicarbonato de sódio, $400.000 \mathrm{U} / \mathrm{ml}$ de penicilina, $40 \mathrm{mg} / \mathrm{ml}$ de Gentamicina, $5 \mathrm{mg} / \mathrm{ml}$ de Anfotericina-B, $15 \mu \mathrm{g} / \mathrm{l}$ de glutationa, com $\mathrm{pH}$ final de 7,0$)$ e, então, cortadas em fragmentos de aproximadamente $1 \mathrm{~mm}^{2}$ usando pinça e tesoura cirúrgicas delicadas e estéreis. Estes fragmentos foram colocados em frascos de poliestireno estéreis para cultura de células, de $25 \mathrm{~mm}^{2}$ (TPP), com $1 \mathrm{ml}$ de meio DMEM/F12, suplementado com $15 \%$ de soro fetal bovino (SFB) e mantidos em estufa a $37^{\circ} \mathrm{C}$, com $5 \%$ de $\mathrm{CO}_{2}$.

A adição de meio DMEM/F12 com SFB a $15 \%$ foi feita a cada 3 dias, com acompanhamento e exames das culturas sob microscópio de inversão, para a observação da morfologia e comportamento dos fibroblastos (aderência, migração e proliferação) até que se obtivesse um número satisfatório de células em cultura, definido pela observação de células com alta atividade mitótica e não confluentes, ocupando aproximadamente $2 / 3$ da capacidade do frasco, quando, então, prosseguiu-se com a repicagem das células.

\subsection{Subcultivo celular}

Para o subcultivo (ou repicagem) das células, retirou-se o meio DMEM/F12 com SFB utilizando pipeta de Pasteur e reali- 
zou-se o enxágüe cuidadoso dos frascos com solução PBS (Phosphate buffered saline). A seguir os mesmos foram incubados com uma solução de EDTA (Gibco - USA) e tripsina Versece $0,2 \%$ (Instituto Adolfo Lutz), durante 3 minutos, em estufa a $37^{\circ} \mathrm{C}$.

Com o microscópio de inversão, observou-se o desprendimento das células e, então, inativou-se a tripsina com a adição de $2 \mathrm{ml}$ de meio DMEM/F12, acrescido com $20 \%$ de SFB. Esta suspensão celular foi, então, dividida em duas partes iguais, ficando uma no mesmo frasco e outra em um novo frasco estéril. Ambos foram colocados novamente em estufa até chegarem à semiconfluência, quando foram novamente subcultivadas, até se chegar ao terceiro subcultivo.

\section{Método para exposição das culturas a ciclosporina}

Foram selecionadas para exposição a ciclosporina $0,05 \%$ (Restasis ${ }^{\circledR}$ - Allergan Laboratórios) as amostras que alcançaram contagem suficiente para a distribuição igualitária em 16 do total de 24 poços dos Multiwells.

Foram distribuídos 5.000 fibroblastos em cada poço, sendo que o método para retirada dessas células em subcultivo foi semelhante aos subcultivos anteriores.

Através da contagem das células, distribuiu-se cada amostra em 16 quantidades iguais de fibroblastos, para que, em cada momento de contagem, fossem utilizados 4 poços dos Multiwells.

Vinte e quatro horas após a distribuição das células nos Multiwells, foi feita a exposição dos fibroblastos a $0,1 \mathrm{ml}$ de ciclosporina $0,05 \%$ em 3 de cada 4 poços que continham os fibroblastos, num total de 12 compartimentos contendo ciclosporina $0,05 \%$ e 4 não expostos (utilizados como controles de não exposição à droga). Todos os 16 poços de cada amostra foram completados com $0,5 \mathrm{ml}$ do meio de cultura (DMEM/ F12 acrescido com $20 \%$ de SFB).

Portanto, a pesquisa em cada um dos indivíduos foi realizada em triplicata, o que torna a contagem dos fibroblastos mais confiável.

Após a exposição das células à ciclosporina, foram feitas as contagens em quatro momentos: a primeira contagem foi realizada 3 dias após a exposição; a segunda 6 dias após a exposição, a terceira 12 dias após a exposição e a quarta contagem foi realizada 17 dias após a exposição.

\section{Metodologia para contagem dos fibroblastos}

O método para contagem de fibroblastos foi através de hemocitômetro (câmara de Neubauer). Primeiramente as células foram expostas à tripsina, de modo a obter uma suspensão homogênea de fibroblastos, sem grumos. Com uma pipeta Pasteur de ponta fina, a suspensão foi homogeneizada, pipetando-se algumas vezes para cima e para baixo. Cinqüenta $\mu \mathrm{l}$ da suspensão foram retirados e diluídos com $50 \mu l$ de azul de metileno, pois o corante marca os fibroblastos inviáveis, para que estes não fossem contados.

Uma amostra foi retirada com pipeta e aplicada nos locais indicados na câmara de Neubauer, de forma que o líquido escorresse por capilaridade entre a lâmina e a lamínula, aguardando-se alguns segundos, focalizando-se e contando-se todas as células do quadrado delimitado grande central (16 quadrados menores), com aumento de 100 vezes.

Como o número de fibroblastos em cada quadrado grande era menor de 100, foram contados 5 quadrados. A concentração foi dada por:

$\frac{\mathrm{n}^{\circ} \text { de células contadas } \mathrm{x} 100^{2}}{\mathrm{n}^{\circ} \text { de quadrados grandes contados }} \times 2=\mathrm{n}^{\circ}$ de fibroblastos $/ \mathrm{ml}$

\section{Análise estatística}

O estudo da contagem de fibroblastos nos dois grupos experimentais e nos 4 momentos de avaliação foi realizado considerando a técnica não-paramétrica da Análise de Variância dos postos para o modelo de medidas repetidas em dois grupos independentes. Todas as discussões dos resultados foram realizadas no nível de $5 \%$ de significância ${ }^{(15)}$.

\section{RESULTADOS}

O subcultivo celular foi possível no material proveniente de 6 portadores de pterígio e 1 cápsula de Tenon normal.

Assim, no material proveniente de 7 pacientes foi possível obter número de fibroblastos suficiente para realizar a exposição em triplicata, controle e contagem em quatro diferentes momentos.

Em todos os quatro momentos de observação $\left(3^{\circ}, 6^{\circ}, 12^{\circ} \mathrm{e}\right.$ $17^{\circ}$ dias), as amostras expostas à droga diferiram estatisticamente dos controles, tendo-se observado que não houve diferença entre as medidas no $3^{\circ}$ e $6^{\circ}$ dias no grupo controle e, nesses dois momentos, a quantidade de células foi menor quando comparada ao $12^{\circ}$ dia e neste, menor que no $17^{\circ}$ dia (Gráfico 1 ).

Quanto ao grupo exposto à droga, no $3^{\circ}$ dia, o número de fibroblastos foi estatisticamente maior que nas contagens subsequientes. Os pacientes 4 e 5 apresentavam fibroblastos viáveis no $12^{\circ}$ dia de exposição, diferentemente dos demais, que já não tinham células contáveis no $12^{\circ}$ dia (Gráfico 2).

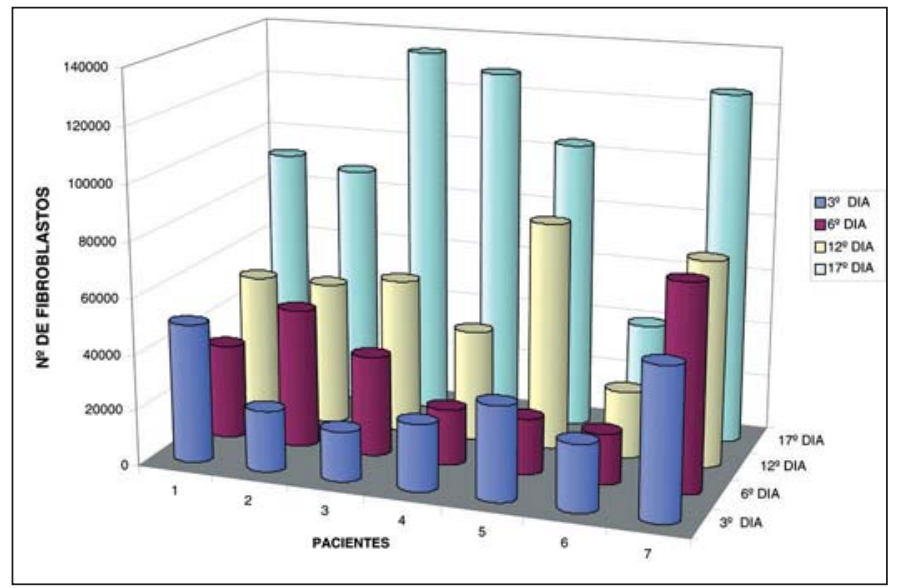

Gráfico 1 - Contagem dos fibroblastos da cápsula de Tenon dos controles, nos quatro momentos de observação 


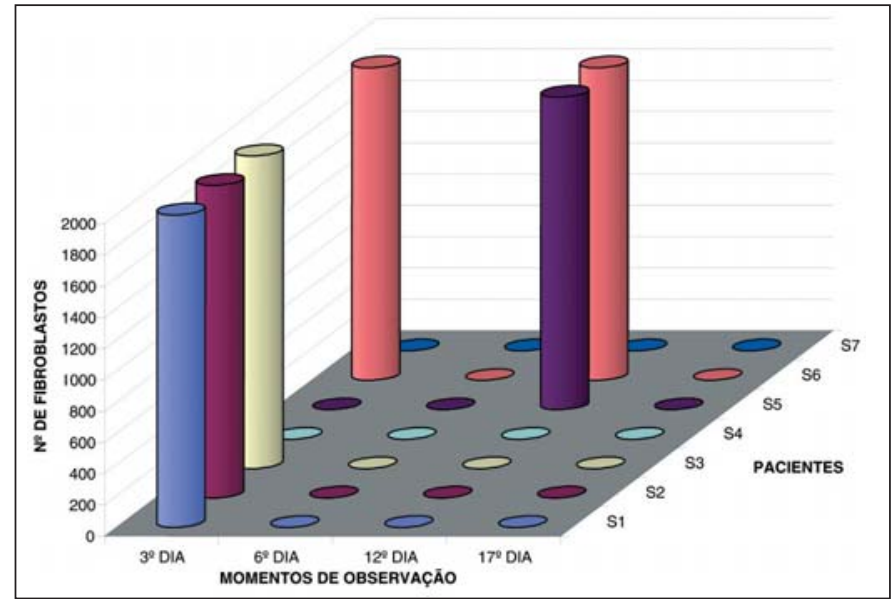

Gráfico 2 - Contagem de fibroblastos expostos à ciclosporina, nos quatro momentos de observação

\section{DISCUSSÃO}

Dentre todas as amostras inicialmente incluídas neste estudo, apenas 7 foram objeto de análise em função das dificuldades de manter as células em cultivo em condições adequadas.

A inviabilidade do cultivo ocorreu devido à ausência de migração dos fibroblastos em alguns casos e à baixa taxa de proliferação destas células em outros, não permitindo que as culturas atingissem a semiconfluência para serem subcultivadas até a terceira passagem, já que são as células de terceira passagem que devem ser utilizadas para a exposição às drogas em experimentos que envolvem cultivo celular.

O crescimento de células em cultivo é dificultoso, havendo necessidade de se controlar o ambiente, fornecer nutrientes e antibióticos ${ }^{(16)}$. Portanto, há necessidade de se coletar um número representativo de amostras para que se consiga obter quantidade expressiva de subcultivos, além de cuidados com a coleta do material, uma vez que pode haver contaminação com células epiteliais com os fibroblastos da cápsula de Tenon, havendo necessidade de se utilizar materiais cirúrgicos e de acondicionamento diferentes para manipulação de cada amostra, para evitar problemas que impeçam a realização do experimento.

Além das dificuldades inerentes para o cultivo e subcultivo de células em cultura, já havia sido observado que a Tenon dos pterígios é mais facilmente cultivável do que a Tenon normal $^{(16)}$. O mesmo foi observado no presente estudo, quando apenas 1 espécime de Tenon normal pôde ser utilizado.

A resposta dos fibroblastos à exposição a ciclosporina não foi uniforme, o que pode ser constatado pela observação do gráfico 2, quando duas amostras apresentavam ainda fibroblastos viáveis 12 dias após a exposição. Esta variabilidade de resposta pode ser a explicação para o fato de alguns indivíduos apresentarem comportamento diferente frente aos procedimentos empregados no tratamento.

Nas condições do estudo, a ciclosporina foi efetiva em evitar a proliferação dos fibroblastos da cápsula de Tenon de pterígios. Até que ponto este resultado pode ser extrapolado para a condição clínica, é um ponto ainda discutível, embora já existam pelo menos dois relatos de emprego clínico da ciclosporina a $1 \%$ ou a $0,05 \%$ para prevenção de recidiva do pterígio $^{(17-18)}$.

Outro tipo de utilização possível poderia ser na profilaxia do crescimento da lesão, possibilitando que o paciente não chegasse à indicação cirúrgica, mas este comentário é ainda especulativo.

Os resultados do presente estudo permitiram conhecer o papel da ciclosporina na proliferação de fibroblastos conjuntivais normais e de pterígios in vitro, mostrando que a droga é efetiva em reduzir esta proliferação. Desta forma, ensaios clínicos devem ser feitos a fim de determinar o papel da ciclosporina como droga coadjuvante para o tratamento do pterígio.

\section{CONCLUSÃO}

A ciclosporina $0,05 \%$ reduziu significativamente a proliferação dos fibroblastos provenientes da cápsula de Tenon de pterígios e normal. Novos estudos devem ser incentivados com o objetivo de estabelecer o real papel da ciclosporina tópica no tratamento do pterígio.

\section{ABSTRACT}

Purpose: To evaluate normal Tenon capsule fibroblasts and from pterygia in culture when exposed to cyclosporin $0.05 \%$. Methods: A prospective, randomized study was done, involving 20 patients with primary pterygium. Samples of normal and pterygium Tenon's capsule from the same individual were collected, cultured and exposed to cyclosporin $0.05 \%$. Results: Only 7 samples could be exposed to cyclosporin - 6 from pterygial Tenon's capsule and 1 from normal Tenon's capsule. There was a significant reduction of cellular proliferation in the cyclosporin exposed cultures $(\mathrm{p}<0.05)$. Conclusion: $\mathrm{Cy}-$ closporin $0.05 \%$ is effective to inhibit the proliferation of pterygia and normal Tenon's capsule fibroblasts. Further studies should be performed to define the role of cyclosporin in pterygium treatment.

Keywords: Pterygium; Cyclosporins, Immunosuppressive agents; Cell culture techniques; Fibroblasts

\section{REFERÊNCIAS}

1. Duke-Elder WS. Textbook of ophthalmology. St Louis: Mosby. 1954. v.7. p.570-86.

2. Kwok LS, Coroneo MT. A model for pterygium formation. Cornea. 1994; 13(3):219-24.

3. Tan DT, Tang WY, Liu YP, Goh HS, Smith DR. Apoptosis and apoptosis related gene expression in normal conjunctiva and pterygium. Br J Ophthalmol. 2000;84(2):212-6.

4. Pyrzynska B, Serrano M, Martinez-A C, Kaminska B. Tumor suppressor p53 mediates apoptotic cell death triggered by cyclosporin A. J Biol Chem. 2002; 277(16):14102-8 
5. Hernandez GL, Volpert OV, Iniguez MA, Lourenzo E, Martinez-Martinez S, Grau R, et al. Selective inhibition of vascular endothelial growth factor mediated angiogenesis by cyclosporin A: roles of the nuclear factor of activated T cells and cyclooxygenase 2. J Exp Med. 2001;193(5):607-20.

6. Liu L, Yang D. Immunological studies on the pathogenesis of pterygium. Chin Med Sci J. 1993;8(2):84-8.

7. Pinkerton OD, Hokama Y, Shigemura LA. Immunologic basis for the pathogenesis of pterygium. Am J Ophthalmol. 1984;98(2):225-8.

8. Kunert KS, Tisdale AS, Stern ME, Smith JA, Gipson IK. Analysis of topical cyclosporine treatment of patients with dry eye syndrome: effect on conjunctival lymphocytes. Arch Ophthalmol. 2000;118(11):1489-96.

9. Perry HD, Donnenfeld ED. Topical $0.05 \%$ cyclosporin in the treatment of dry eye. Expert Opin Pharmacother. 2004;5(10):2099-107.

10. Pucci N, Novembre E, Cianferoni A, Lombardi E, Bernardini R, Caputo R, et al. Efficacy and safety of cyclosporine eyedrops in vernal keratoconjunctivitis. Ann Allergy Asthma Immunol. 2002;89(3):298-303.

11. Bhargava A, Jackson WB, El-Defrawy SR. Ocular allergic disease. Drugs Today (Barc). 1998;34(11):957-71.

12. Leonardi A, DeFranchis G, Fregona IA, Violato D, Plebani M, Secchi AG
Effects of cyclosporin A on human conjunctival fibroblasts. Arch Ophthalmol. 2001;119(10):1512-7.

13. Strong B, Farley W, Stern ME, Pflugfelder SC. Topical cyclosporine inhibits conjunctival epithelial apoptosis in experimental murine keratoconjunctivitis sicca. Cornea. 2005;24(1):80-5.

14. Theng J, Zhou L, Tan D, La KW. Distribution of cyclosporin A in the cornea after topical or oral administration. J Ocul Pharmacol Ther. 2002;18(1):83-8.

15. Norman GR, Streiner DL. Biostatistics: the bare essentials. St. Louis: Mosby. 1994. 240p.

16. Viveiros MMH, Schellini SA, Rainho C, Rogatto SR, Padovani CR. Análise do cultivo de fibroblastos da cápsula de Tenon de pterígios primários e recidivados [abstract]. Arq Bras Oftalmol. 2004;67(4 Supl):37. [Resumos dos Temas Livres do XVI Congresso Brasileiro de Prevenção da Cegueira e Reabilitação Visual].

17. Wu H, Chen G. [Cyclosporine A and thiotepa in prevention of postoperative recurrence of pterygium]. Yan Ke Xue Bao. 1999;15(2):91-2. Chinese.

18. Hasegawa DS, Hoyama E, Dalamas JC, Hasegawa N, Yagui N. Uso de ciclosporina $0,05 \%$ colírio no pós-operatório do pterígio [abstract]. In: XXX International Congress of Ophthalmology; $2006 \mathrm{Feb}$ 19-24. Abstract Book. São Paulo. 2006. p.64. 